\title{
Identification and Preliminary Characterization of AcsF, a Putative Ni-Insertase Used in the Biosynthesis of Acetyl-CoA Synthase from Clostridium thermoaceticum
}

Huay-Keng Loke ${ }^{\mathrm{a}}$, and Paul A. Lindahl ${ }^{\mathrm{a}, \mathrm{b}, *}$

${ }^{a}$ Department of Chemistry, College of Science, Texas A\&M University, College Station, Texas

77843 and the ${ }^{b}$ Department of Biochemistry and Biophysics, College of Agriculture and Life

Sciences, Texas A\&M University, College Station, Texas 77843

*Corresponding author. Tel.: 979-845-0956; fax: 979-845-4719; e-mail address:

Lindahl@mail.chem.tamu.edu 


\begin{abstract}
The acs $A B C D E$ genes in the Clostridium thermoaceticum genome are used for autotrophic acetyl-CoA synthesis using the Wood/Ljungdahl pathway. A $2.8 \mathrm{~kb}$ region between $\operatorname{acs} C$ and $a c s D$ was cloned and sequenced. Two open reading frames, orf7 $(\sim 1.9 \mathrm{~kb})$ and $\operatorname{acs} F$ $(\sim 0.7 \mathrm{~kb})$ were identified. orf7 appears to encode an Fe-S protein, in that it contains 5 conserved cysteine residues, 3 of which are present in a motif (CXXXXXCXXC) commonly used to coordinate Fe-S clusters. However, Orf7 is probably not involved in autotrophic acetylCoA synthesis, as homologous genes are present in organisms that do not utilize this pathway and are absent in many that do. In contrast, $a c s F$ is probably involved in this pathway. Sequence alignment of AcsF and 11 homologs reveals a number of conserved regions, including a P-loop that binds nucleoside triphosphates and catalyzes their hydrolysis. One homolog is CooC, an ATPase/GTPase that inserts Ni into a precursor form of the C-cluster of the carbon monoxide dehydrogenase (CODH) from Rhodospirillum rubrum. Purified AcsF lacked Ni and Fe, and slowly catalyzed the hydrolysis of ATP. Such similarities to CooC suggest that AcsF may function to insert $\mathrm{Ni}$ into a Ni-deficient form of the bifunctional acetyl-CoA synthase/CODH from $C$. thermoaceticum $\left(\mathrm{ACS}_{\mathrm{Ct}}\right)$. However, this could not be established, as expression of acs $F$ did not effect activation of recombinant AcsAB expressed in E. coli. Also, E. coli cells defective in $h y p B$ retained the ability to synthesize active recombinant AcsAB. Rather, the concentration of extracellular $\mathrm{Ni}^{2+}$ ions was critical to activation.
\end{abstract}


This article is dedicated to Professor William H. Orme-Johnson, graduate advisor and mentor of one of the authors (P.A.L.).

\section{Introduction}

Within a few months of joining Bill's lab at MIT in 1980, and at the start of my graduate work on iron-sulfur centers in nitrogenase, I began to wonder how such clusters were formed in enzymes. I eventually asked Bill about this, as he was a wealth of information on an incredibly wide range of topics, from the fundamentals of physics, chemistry, and biochemistry to practical topics such as how to blow glass or measure the oxygen permeability of rubber tubing. "Well my boy", he replied with his characteristic grin, "I'm afraid that no one knows the answer to that, though synthetic $\mathrm{Fe}_{4} \mathrm{~S}_{4}$ clusters are known to self-assemble.” A little disappointed that more was not known, I concluded that Fe-S proteins must simply sequester free metal and sulfide ions from the cytoplasm and assemble their centers spontaneously.

In the past 20 years, it has become apparent that such processes are far more complicated than I had assumed. Evidence suggests that free metal concentrations in cells are quite low, and that "chaperone" accessory proteins play major roles in metal ion transport and metal center assembly [1,2]. For example, $\mathrm{Fe}_{4} \mathrm{~S}_{4}$ clusters are built by accessory proteins IscU and IscS (or their homologs), and then inserted into target proteins [3-7]. Some insertion processes require ATP or GTP hydrolyzing enzymes. They probably use the free energy of hydrolysis to pry open the site of the target proteins into which metal ions insert.

The mechanisms used to insert Ni into the apo-proteins of urease, Ni-hydrogenases, and Ni-containing carbon monoxide dehydrogenases have been studied extensively. Hausinger and coworkers have found that $u r e D A B C E F G$ genes control the biosynthesis and maturation of 
urease from Klebsiella aerogenes [8]. Genes ureDEFG encode accessory proteins that assemble a dinuclear Ni-center in apo-urease (UreABC) $[9,10]$. UreD binds and stabilizes apo-urease in a conformation receptive to Ni-insertion [11,12], while UreF binds the complex and prevents $\mathrm{Ni}$ ions from inserting until a lysine at the active site is carbamylated [13]. UreG binds GTP at a conserved P-loop region [14,15]. UreE contains a sequence of 10 histidine residues at the Cterminus [9], and forms a homodimer that binds up to six Ni ions [16]. Two of these Ni ions appear to insert into the protein complex, then UreG-associated nucleotides hydrolyze, and active enzyme forms as UreDFG proteins dissociate.

Böck and co-workers found that the hyc and hyp operons in Escherichia coli control the synthesis of the Hase3 NiFe hydrogenase and the assembly of the NiFe active site in HycE [1719]. HycE is synthesized in an inactive Ni-free precursor form (pre-HycE) with a C-terminal "tail" that stabilizes the protein conformation required for Ni-insertion [20,21]. HypB contains a nucleotide-binding domain similar to that in UreG. It binds GDP, exhibits GTPase activity [22], and is essential for Ni-insertion [23]. HypC binds pre-HycE [24,25], while HycI is a protease that cleaves the pre-HycE tail as $\mathrm{Ni}$ inserts, thereby changing the conformation of $\mathrm{HycE}$ $[20,26,27]$. This cleavage-induced conformational change is an irreversible trap that buries $\mathrm{Ni}$ into the protein interior.

Carbon monoxide dehydrogenase from Rhodospirillum rubrum $\left(\mathrm{CODH}_{\mathrm{Rr}}\right)$ is a homodimer that catalyzes the reversible oxidation of $\mathrm{CO}$ to $\mathrm{CO}_{2}[28,29]$. $\mathrm{CODH}_{\mathrm{Rr}}$ contains three types of metal-sulfur clusters (B-, C-, and D-clusters) [30]. The B- and D-clusters are $\mathrm{Fe}_{4} \mathrm{~S}_{4}$ clusters involved in electron transfer reactions, while the C-cluster is a $\mathrm{NiFe}_{4} \mathrm{~S}_{4-5}$ structure that serves as the active site for $\mathrm{CO} / \mathrm{CO}_{2}$ redox catalysis [30]. 
Roberts, Ludden, and coworkers have found that the coo operon (cooFSCTJ) is responsible for synthesizing $\mathrm{CODH}_{\mathrm{Rr}}$ and inserting $\mathrm{Ni}$ [31]. CooS is the structural subunit of $\mathrm{CODH}_{\mathrm{Rr}}$ while $\mathrm{CooF}$ is an associated ferredoxin. $\mathrm{CooC}, \mathrm{CooT}$, and $\mathrm{CooJ}$ are required for $\mathrm{C}-$ cluster assembly. CooC is $62 \mathrm{kDa}$ homodimer that contains a nucleotide-binding P-loop region [31] and hydrolyzes both ATP and GTP [32]. Deletion of $\operatorname{coo} C$ results in a $\mathrm{CODH}_{\mathrm{Rr}}$ that has its $\mathrm{B}$ - and D-clusters intact, while the $\mathrm{C}$-cluster is in a precursor form that contains the Fe-S portion but lacks $\mathrm{Ni}$ [31]. This Ni-deficient form of $\mathrm{CODH}_{\mathrm{Rr}}$ can be activated in vitro by simply incubating samples in $\mathrm{NiCl}_{2}$ under reducing conditions [33]. Site-directed mutagenesis reveals that the P-loop is required for ATP hydrolysis and in vivo Ni-insertion $[31,32]$. CooT is homologous to HypC and may be involved in metal-ion discrimination [31]. CooJ has a histidine-rich C-terminus, and binds up to 4 Ni's per monomer [34].

The bifunctional enzyme acetyl-coenzyme A synthase/carbon monoxide dehydrogenase from Clostridium thermoaceticum $\left(\mathrm{ACS}_{\mathrm{Ct}}\right.$ ) is an $\alpha_{2} \beta_{2}$ tetramer [35] in which the $\beta$ subunits are homologous to $\mathrm{CODH}_{\mathrm{Rr}}$. In addition to the $\mathrm{B}-, \mathrm{C}-$, and D-clusters in the $\beta$ subunits, a Ni-X$\mathrm{Fe}_{4} \mathrm{~S}_{4}$ center known as the A-cluster is located in the $\alpha$ subunit and is the site of acetyl-CoA synthesis [35-39]. $\mathrm{ACS}_{\mathrm{Ct}}$, a heterodimeric corrinoid-iron-sulfur protein (CoFeSP), and a methyltransferase are among the enzymes used in the Wood-Ljungdahl pathway for the autotrophic synthesis of acetyl-CoA from $\mathrm{CO}_{2}$ [40]. These enzymes are encoded by acsABCDE [41,42]. Genes acs $A$ and $a c s B$ encode the $\beta(73 \mathrm{kDa})$ and $\alpha(82 \mathrm{kDa})$ subunits of $\mathrm{ACS}_{\mathrm{Ct}}$, respectively; $a c s C$ and $a c s D$ encode the large and small subunits of CoFeSP, and $a c s E$ encodes methyltransferase (Figure 1).

In this paper, we report the cloning and sequencing of two open reading frames (ORF's), one of which is a gene $(a c s F)$ that may encode an accessory protein required for inserting $\mathrm{Ni}$ into 
a Ni-deficient precursor form of $\mathrm{ACS}_{\mathrm{Ct}}$ that contains Fe-S clusters but lacks Ni. We also report the results of overexpressing $a c s F$, as well as a preliminary characterization of the protein. This is the first report regarding a protein that may be responsible for $\mathrm{Ni}$ insertion during the maturation of $\mathrm{ACS}_{\mathrm{Ct}}$.

\section{Experimental}

\subsection{Cloning and DNA Sequence Determinations of 2 ORF's}

PCR primers that hybridize to nucleotide sequences within $\operatorname{acs} C$ and $\operatorname{acs} D$, 5'-GGCGGCCGCGGGGGCCAACCTGGCTTCATAG-3' and 5'-GGCGGCATATGCGTAAAATCTGGACGGCCAT-3', were synthesized by the Gene Technologies Laboratory (GTL), Texas A\&M University. The unreported region between these primers was amplified from genomic DNA of C. thermoaceticum using the primers, Taq polymerase, (Applied Biosystems), an MJ Research Minicycler ${ }^{\mathrm{TM}}$, and a PCR Optimizer Kit (Invitrogen). The resulting $2.8 \mathrm{~kb}$ PCR product was ligated with the TA cloning vector and transformed into INV $\alpha$ F' cells (TA Cloning ${ }^{\circledR}$ Kit, Invitrogen). pORF5 was isolated from cells resistant to ampicillin and sequenced at the GTL.

\subsection{Analyses of Predicted Amino Acid Sequences of orf7 and acsF}

ORF's were identified using Genetics Computer Group [GCG] MAP routine. The pI's and molecular weights of the deduced amino acid sequences were analyzed using the Expert 
Protein Analysis System (ExPASy) proteomics server of the Swiss Institute of Bioinformatics (SIB). Homologous protein sequences were obtained from the GenBank database at the National Center for Biotechnology Information (Bethesda, Md.) using the network server BLAST. Protein sequences were aligned at the GENESTREAM network server of IGH, Montpellier, France, and by visual inspection.

\subsection{Subcloning and Expression of acsF}

Gene $a c s F$ was amplified from $C$. thermoaceticum genomic DNA as described above except using primers 5'-GGCGGGGATCCGGATGGCCCGTCATATTGCC-3' and 5'GGCGGGAATTCTTAAAACTGGCATCGGGC-3'. The resulting purified $0.7 \mathrm{~kb}$ PCR product and vector pGEX-3X (Amersham Pharmacia Biotech) were digested with EcoRI and BamHI (New England Biolabs) and then ligated. The ligation mixture was transformed into XL1-Blue cells (Stratagene) and plasmid pNH03 was isolated from ampicillin-resistant cells. This vector was used to produce a fusion protein of glutathione S-transferase (GST) with AcsF. E. coli BL21(DE3) (Amersham Pharmacia Biotech) containing pNH03 were grown in $25 \mathrm{~L}$ of ampicillin-supplemented Begg's medium [43] at $30^{\circ} \mathrm{C}$ under anaerobic conditions and induced with $0.05 \mathrm{mM}$ IPTG and supplemented with $0.1 \mathrm{mM} \mathrm{NiCl}_{2}$ at $15^{\circ} \mathrm{C}$. Cells were harvested anaerobically. Production of the fusion protein was detected using the Western Blot method with GST antibodies and anti-rabbit IgG (Fc) AP conjugate [44].

\subsection{Purifications of AcsF-GST and GST}


Ten $\mathrm{g}$ of BL21(DE3) (pNH03) cells were suspended in $100 \mathrm{~mL}$ of Buffer A (140 mM $\mathrm{NaCl}, 2.7 \mathrm{mM} \mathrm{KCl}, 10 \mathrm{mM} \mathrm{Na} 2 \mathrm{HPO}_{4}, 1.8 \mathrm{mM} \mathrm{KH}_{2} \mathrm{PO}_{4} \mathrm{pH} 7.3,2 \mathrm{mM}$ sodium dithionite, $10 \mathrm{mM}$ DTT) containing $10 \mathrm{mg}$ of lysozyme and a trace of DNase for $30 \mathrm{~min}$ under anaerobic conditions [45]. The suspension was sonicated for 1.5 min using $1 \mathrm{~s}$ pulses (Branson Sonifier 450) and spun down for $30 \mathrm{~min}$ at 23,500 X g with a GSA rotor (Sorvall). The supernatant was loaded onto a 3 $\mathrm{mL}$ column of Glutathione Sepharose 4B (Amersham Pharmacia Biotech) pre-equilibrated with $30 \mathrm{~mL}$ of Buffer A. The column was washed with $100 \mathrm{~mL}$ of Buffer A and the protein eluted with $5 \mathrm{~mL}$ of $10 \mathrm{mM}$ reduced glutathione in Buffer A. GST was similarly purified from BL21(DE3) (pGEX-3X) (grown under the same conditions as BL21(DE3) (pNH03)).

\subsection{Characterization of AcsF-GST}

Sample purities, metal analyses, and protein concentrations were quantified as described [46]. The ATP assay mixture is a solution of Buffer A containing $5 \mathrm{mM} \mathrm{MgCl}_{2}$ and $1 \mathrm{mM} \mathrm{ATP \text {, }}$ and the GTP assay mixture is a solution of Buffer A containing $5 \mathrm{mM} \mathrm{MgCl}_{2}$, and $1 \mathrm{mM} \mathrm{GTP}$. Assay mixtures were incubated at $30^{\circ} \mathrm{C}$ under an $\mathrm{Ar}$ atmosphere and reactions were initiated with the addition of AcsF-GST or GST to a final protein concentration of $2 \mu \mathrm{M} .40 \mu \mathrm{L}$ samples from a $500 \mu \mathrm{L}$ reaction mixture were injected into a Whatman* Partisil* $5 \mathrm{SAX}(4.6 \mathrm{~mm} \mathrm{X} 10 \mathrm{~cm})$ column every 2 - 3 hrs to separate ADP or GDP from unhydrolyzed ATP or GTP in a $0.5 \mathrm{M}$ $\mathrm{NH}_{4} \mathrm{HPO}_{4} \mathrm{pH} 4.0$ mobile phase at $1.0 \mathrm{mLmin}^{-1}$ [47]. The amount of ADP or GDP produced with time was measured and quantified at $254 \mathrm{~nm}$ using HPLC/UV-visible spectroscopy. Control reactions containing only the assay mixtures were set up to monitor the background hydrolysis of ATP and GTP. 


\subsection{Subcloning of acsF into pTM02}

Gene $a c s F$ was amplified from pORF5 using primers 5'-GGCGGAAGCTTCGACGAAAGGAGGTCGGG-3' and 5'-GGCGGTCTAGATTAAAACTGGCATCGGGCC-3' as described above, except using $P f u$ Turbo polymerase (Stratagene). The resulting purified $0.7 \mathrm{~kb}$ PCR product and plasmid pTM02 [46] were digested with HindIII and XbaI (New England Biolabs). The digested $0.7 \mathrm{~kb}$ PCR product and the $6.0 \mathrm{~kb}$ fragment of digested pTM02 were ligated. The ligation mixture was transformed into XL1-Blue cells (Stratagene) and plasmid pHX06 was isolated from ampicillinresistant cells. Subsequently, pHX06 and pTM02 were digested with HindIII. Digested pHX06 was treated with alkaline phosphatase (Promega) before ligation to the $2.7 \mathrm{~kb}$ fragment of digested pTM02. Plasmid pLHE02, which contains $a c s A B F$, was isolated from ampicillinresistant cells.

\subsection{Characterization of AcsAB from JM109 (pTM02) and JM109 (pLHE02)}

E. coli JM109 (pTM02) and JM109 (pLHE02) were grown in 25 L's of ampicillinsupplemented Begg's media [43] and induced with IPTG and supplemented with $\mathrm{NiCl}_{2}$ as previously reported [46]. Production of the gene product of $a \operatorname{cs} A B$ lacking metal ions was detected using the Western Blot method. CO oxidation activities were monitored as described [46]. 


\section{Results}

\subsection{Identification and Sequencing of orf7 and acsF}

As illustrated in the Introduction, bacterial genes that encode proteins used to assemble and install metal centers in metalloenzymes are often located in the same operon as the structural genes for the target metalloenzyme. We noticed that the nucleotide sequence of the $2.8 \mathrm{~kb}$ region between $a c s C$ and $a c s D$ had not been reported, and hence we cloned and sequenced it. Two ORF's were identified and designated $\operatorname{orf} 7$ and $a c s F .{ }^{1}$ Genes orf 7 and $a c s F$ are $\sim 1.9 \mathrm{~kb}$ and $\sim 0.7 \mathrm{~kb}$ in lengths, respectively. The region of the acs operon is now completed, as shown in Figure 1.

The corresponding Orf7 protein is predicted to consist of 637 residues and have a molecular weight of $62 \mathrm{kDa}$ with a pI of 4.95 . Its sequence is homologous to hypothetical proteins in Archaeoglobus fulgidus, Mesorhizobium loti, and Sinorhizobium meliloti. Alignment of these sequences reveals 5 conserved cysteine residues, 3 of which are present in a motif (CXXXXXCXXC) commonly used to coordinate Fe-S clusters (Figure 2) [48].

acs $F$ is predicted to encode a $27 \mathrm{kDa}$ protein consisting of 249 residues with a $\mathrm{pI}$ of 4.96 . The start ATG codon of acsF overlaps orf7 by one basepair. BLAST searches reveal that AcsF is homologous to 11 other proteins. All of the organisms that contain AcsF homologs, including Methanobacterium thermoautotrophicum, Methanococcus jannaschii, Methanosarcina thermophila, A. fulgidus, and R. rubrum are either archaea or bacteria that contain

\footnotetext{
${ }^{1}$ The nucleotide sequence of this region appears in the GenBank sequence database under accession code XXX.
} 
ACS/CODH's. Conserved throughout these sequences include a P-loop region ${ }^{2}$ at the Nterminus, a region containing two aspartates (DXD), a region containing two cysteines (GCXC), and a region containing a number of potential metal-coordinating residues (DXEAGXEHXXR) (Figure 3). The P-loop motif is also observed in UreG, HypB, and CooC, GTP/ATPases used to insert Ni into urease, Ni-hydrogenase, and CO dehydrogenase from R. rubrum, respectively.

\subsection{Purification and Characterization of AcsF}

A genetic chimera of $a c s F$ and the gene encoding glutathione-S-transferase was prepared and expressed in $E$. coli at $15^{\circ} \mathrm{C}$. The tac promoter used in this construct allowed induction with $0.05 \mathrm{mM}$ IPTG. The resulting AcsF-GST fusion protein $(\sim 55 \mathrm{kDa})$ was soluble. Protein purity was assessed using an Alphaimager 2000 (Alpha Innotech Corp). Approximately 80\% pure AcsF-GST and GST were obtained in one-step purifications using an affinity column (Figure 4). Metal analyses revealed that AcsF-GST contained less than $0.1 \mathrm{Ni} / \mathrm{mol}$ and undetectable amounts of iron. AcsF-GST exhibited low ATPase activity $\left(\sim 0.3 \mathrm{nmolmin}^{-1} \mathrm{mg}^{-1}\right)$ but no GTPase activity (Figure 5). A control experiment involving GST in the absence of AcsF exhibited essentially no activity.

\subsection{Investigating the Physiological Function of AcsF}

\footnotetext{
${ }^{2}$ The predicted sequence of one of the homologous proteins from M. thermophila [49] lacked the P-loop region. However, inspection of the nucleotide sequence just prior to the reported start codon revealed a P-loop segment. We have included that segment in our sequence alignment, and suggest that it corresponds to the N-terminus of that protein, and that the actual start codon is upstream of this region.
} 
Genes $a \operatorname{cs} A B$ were previously cloned and expressed in E. coli JM109 (pTM02) to produce a form of $\mathrm{Acs} \mathrm{AB}$ with $\mathrm{CO}$ oxidation activity comparable to $\mathrm{ACS}_{\mathrm{Ct}}[46]$. This indicates that the $\mathrm{B}$ - and D-clusters of $\mathrm{ACS}_{\mathrm{Ct}}$ and the Fe-S portion of the $\mathrm{C}$-cluster were properly assembled/inserted by an organism (ie. E. coli) that does not naturally contain $\mathrm{ACS}_{\mathrm{Ct}}$ or (presumably) accessory proteins specifically required for these processes. Other accessory proteins naturally found in E. coli may have served as surrogates. We previously proposed that the $E$. coli enzymes IscU and IscS assembled the Fe-S clusters in recombinant AcsAB, and that HypB served as a surrogate accessory protein for inserting Ni during assembly of the C-cluster [46]. To test this hypothesis, a hyp $B^{-}$strain of JM109 was constructed as described [19] using plasmid pDB507. Surprisingly, the recombinant AcsAB obtained when acs $A B$ genes were expressed in this HypB-deficient strain and grown in Ni-supplemented Begg's medium had CO oxidation activities comparable to Acs AB obtained from cells with HypB (Table 1). This implies that $\mathrm{HypB}$ is not responsible for inserting $\mathrm{Ni}$ into the precursor form of the C-cluster.

To further examine the physiological role of AcsF, 4 batches of cells were grown under different conditions, and the resulting recombinant $\mathrm{Acs} A \mathrm{~B}$ was purified and assayed for $\mathrm{CO}$ oxidation activity. When $\operatorname{acs} A B$ were expressed in cells that were not supplemented with $\mathrm{Ni}$, the resulting $\mathrm{Acs} A \mathrm{~B}$ had virtually no $\mathrm{CO}$ oxidation activity, while recombinant $\mathrm{Acs} A \mathrm{~B}$ obtained in cells that were supplemented with Ni had full activity. Similarly, when genes acs $A B F$ were expressed in cells that were not supplemented with $\mathrm{Ni}$, the resulting AcsAB was inactive, while Acs AB obtained from cells supplemented with Ni had high activity. Thus, supplementing the $E$. coli growth medium with $\mathrm{Ni}^{2+}$ ions $(5 \mu \mathrm{M}$ vs. $500 \mu \mathrm{M})$ was important in activating $\mathrm{Acs} A \mathrm{~B}$, while the presence of AcsF appears irrelevant. 


\section{Discussion}

We have identified and sequenced two ORF's located within a group of genes that encode enzymes of the Wood/Ljungdahl pathway of autotrophic acetyl-CoA synthesis in Clostridium thermoaceticum (acs $A B C$ and $a c s D E$ ). Sequence alignments suggest that one of these regions (orf7) encodes an Fe-S protein. Since none of the homologous proteins has been purified or characterized, the role of this putative Fe-S protein remains uncertain. It seems unlikely that it is associated with the Wood/Ljungdahl pathway, as orf7 homologs are found in organisms that do not contain genes that encode $\mathrm{CODH}$ or ACS, and is not found in every organism that does contain these enzymes.

In contrast, $a c s F$ appears to be associated with the pathway. The evidence for this is as follows. First, acsF is located within the region containing acs genes. Second, homologs of acsF are found exclusively in organisms that contain enzymes of the CODH family. Third, deletion of $\operatorname{coo} C$ (an acsF homolog) in $R$. rubrum results in a Ni-deficient form of CODH $\mathrm{Rr}_{\text {. }}$ Fourth, CooC and AcsF both slowly catalyze the hydrolysis of purine nucleoside triphosphates (ATP and/or GTP).

The organisms that contain $a c s F$-homologs often contain more than one homologous gene. For example, $M$. thermoautotrophicum and $M$. jannaschii contain 3 acsF-homologs each, while $M$. thermophila and A. fulgidus contains 2 such homologs each. Additional acsFhomologs may be found in C. thermoaceticum and $R$. rubrum for which just 1 such sequence has been found, as the genomes of these organisms have not been sequenced.

The low nucleoside triphosphate hydrolysis activity and lack of $\mathrm{Ni}$ and $\mathrm{Fe}$ ions of AcsF are similar to the properties observed for $\mathrm{CooC}$ [32]. Such observed low hydrolysis activity is typical of nucleoside-dependent proteins that bind to and stabilize other proteins in 
conformations required for subsequent processing. ATP or GTP hydrolysis may be triggered by the formation of such complexes. In the case of $\mathrm{AcsF}$ and $\mathrm{CooC}$, this might provide free energy needed for a conformational change, $\mathrm{Ni}$ insertion, and subsequent dissociation of the proteins. The low activity observed with both proteins may reflect nonphysiological "basal" levels. More rapid hydrolysis may occur only when these proteins are bound to their appropriate (and as of yet unidentified) protein substrates. This assumed role of AcsF and CooC as ATP or GTPhydrolyzing Ni insertases would be analogous to the processing of other Ni-containing enzymes, including urease and NiFe hydrogenases.

Despite the evidence just presented suggesting that AcsF is an ATP-hydrolyzing Ni insertase, this hypothesis has not been firmly established by our subsequent experiments. First, the requirement of AcsF for Ni-insertion into Ni-deficient AcsAB in E. coli could not be established, as expression of acsAB in this AcsF-lacking organism resulted in an ACS with full CO oxidation activity. We had proposed that the HypB in E. coli served as a surrogate for AcsF, but active $\mathrm{ACS}_{\mathrm{Ct}}$ was also obtained when overexpressed in an E. coli strain lacking hypB, as long as the strain was grown on Ni-supplemented media. Thus, the only critical variable in determining whether recombinant $\mathrm{Acs} A \mathrm{~B}$ was activated was the Ni concentration of the growth medium.

It is tempting to conclude from these studies that AcsF is not involved in activating $\mathrm{ACS}_{\mathrm{Ct}}$, but our results should be interpreted cautiously, as Ni metabolism in E. coli is not fully understood and is undoubtedly complicated. Moreover, similar effects have been observed in other systems. High concentrations of $\mathrm{Ni}$ ions in the growth media of E. coli "overcome" the effect of deleting hypB on the processing of Hase3 [22]. Similar suppression effects by high Ni concentrations have also been reported for the processing of urease and $\mathrm{CODH}_{\mathrm{Rr}}$ when $\mathrm{UreG}$ and 
$\mathrm{CooC}$ are absent $[8,31]$. In addition, the insertion of $\mathrm{Cu}$ ions into $\mathrm{CuZn}$-superoxide dismutase which requires the presence of the chaperone, CCS can also be overcome in strains devoid of CCS by high extracellular $\mathrm{Cu}$ ion concentrations in the growth media [1].

Curiously, supplementing growth media with concentrations of metal ions sufficient to suppress these processing defects generally inhibits cell growth, suggesting the presence of new deleterious processes under these growth conditions. Might high external metal ion concentrations cause high intracellular metal ion concentrations - high enough to activate these enzymes and cause cellular damage? Interestingly, Bill Orme-Johnson's earlier suggestion that free metal ions are involved in in vivo metal center assembly appears to offer a possible explanation for the results of these experiments. Of course, further studies are required to assess this possibility and the physiological role of AcsF. These might involve in vitro protein synthesis under controlled metal ion conditions and/or the ability to measure free metal ion concentrations within cells.

\author{
Abbreviations \\ $\mathrm{ACS}_{\mathrm{Ct}}$, acetyl-CoA synthase from $C$. thermoaceticum (also known as Moorella thermoacetica), \\ also called carbon monoxide dehydrogenase or $\mathrm{CODH}_{\mathrm{Ct}}$; $\mathrm{Acs} \mathrm{AB}$, recombinant protein produced \\ by expressing $C$. thermoaceticum acs $A$ and $a \operatorname{cs} B$ genes in $E$. coli; Hase3, NiFe hydrogenase 3 \\ from E. coli; GST, glutathione S-transferase; CCS, copper chaperone for CuZn-superoxide \\ dismutase.
}

\title{
Acknowledgements
}


We thank Professor August Böck from Lehrstuhl für Mikrobiologie der Universität München, Germany for the kind gift of plasmid pDB507. This work was supported by the Department of Energy Grant DE-FG03-01ER15177 and National Institutes of Health Grant GM46441.

\section{References}

[1] T. D. Rae, P. J. Schmidt, R. A. Pufahl, V. C. Culotta, T. V. O'Halloran, Science 284 (1999) 805-808.

[2] T. V. O'Halloran, V. C. Culotta, J. Biol. Chem. 275 (2000) 25057-25060.

[3] D. R. Dean, J. T. Bolin, L. Zheng, J. Bacteriol. 175 (1993) 6737-6744.

[4] L. Zheng, V. L. Cash, D. H. Flint, D. R. Dean, J. Biol. Chem. 273 (1998) 13264-13272.

[5] L. Zheng, R. H. White, V. L. Cash, R. F. Jack, D. R. Dean, Proc. Natl. Acad. Sci. USA 90 (1993) 2754-2758.

[6] P., Yuvaniyama, J. N. Agar, V. L. Cash, M. K. Johnson, D. R. Dean, Proc. Natl. Acad. Sci. USA 97 (2000), 599-604.

[7] J. N. Agar, L. Zheng, V. L. Cash, D. R. Dean, M. K. Johnson J. Am. Chem. Soc. 122 (2000) 2136-2137.

[8] H. L. T. Mobley, M. D. Island, R. P. Hausinger, Microbiol. Rev. 59 (1995), 451-480.

[9] S. B. Mulrooney, R. P. Hausinger, J. Bacteriol. 172 (1990), 5837-5843.

[10] M. H. Lee, S. B. Mulrooney, M. J. Renner, Y. Markowicz, R. P. Hausinger, J. Bacteriol. 174 (1992), 4324-4330.

[11] I. S. Park, M. B. Carr, R. P. Hausinger, Proc. Natl. Acad. Sci. USA 91 (1994) 3233-3237.

[12] I. S. Park, R. P. Hausinger, J. Bacteriol. 177 (1995) 1947-1951. 
[13] M. B. Moncrief, R. P. Hausinger, J. Bacteriol. 178 (1996) 5417-5421.

[14] M. B. Moncrief, R. P. Hausinger, J. Bacteriol. 179 (1997) 4081-4086.

[15] A. Soriano, R. P. Hausinger, Proc. Natl. Acad. Sci. USA 96 (1999) 11140-11144.

[16] M. H. Lee, H. S. Pankratz, S. Wang, R. A. Scott, M. G. Finnegan, M. K. Johnson, J. A. Ippolito, D. W. Christianson, R. P. Hausinger, Protein Sci. 2 (1993) 1042-1052.

[17] M. Sauter, R. Bohm, A. Böck, Molecular Microbiology 6 (1992) 1523-1532.

[18] S. Lutz, A. Jacobi, V. Schlensog, R. Bohm, G. Sawers, A. Böck, Molecular Microbiology 5 (1991), 123-135.

[19] A. Jacobi, R. Rossman, A. Böck, Arch. Microbiol. 158 (1992) 444-451.

[20] R. M. Rossman, M. Sauter, F. Lottspeich, A. Böck, Eur J. Biochem. 220 (1994) 377-384.

[21] T. Maier, A. Böck, A. Mechanisms of Metallocenter Assembly (Hausinger, R. P. Ed.), VCH, New York (1996) 173-192.

[22] T. Maier, A. Jacobi, M. Sauter, A. Böck, J. Bacteriol. 175 (1993) 630-635.

[23] T. Maier, F. Lottspeich, A. Böck, Eur. J. Biochem. 230 (1995) 133-138.

[24] N. Drapal, A. Böck, Biochemistry 37 (1998) 2941-2948.

[25] A. Magalon, A. Böck, J. Biol. Chem. 275 (2000) 21114-21120.

[26] R. M. Rossman, T. Maier, F. Lottspeich, A. Böck, Eur. J. Biochem. 227 (1995) 545-550.

[27] T. Maier, A. Böck, Biochemistry 35 (1996) 10089-10093.

[28] R. L. Kerby, S. S. Hong, S. A. Ensign, L. J. Coppoc, P. W. Ludden, G. P. Roberts, J. Bacteriol. 174 (1992), 5284-5294.

[29] D. Bonam, P. W. Ludden, J. Biol. Chem. 262 (1987) 2980-2987.

[30] C. L. Drennan, J. Heo, M. D. Sintchak, E. Schreiter, P. W. Ludden, Proc. Natl. Acad. Sci. USA 98 (2001) 11973-11978. 
[31] R. L. Kerby, P. W. Ludden, G. P. Roberts, J. Bacteriol. 179 (1997) 2259-2266.

[32] W. B. Jeon, J. Cheng, P. W. Ludden, J. Biol. Chem. 276 (2001) 38602-38609.

[33] S. A. Ensign, M. J. Campbell, P. W. Ludden, Biochemistry 29 (1990) 2162-2168.

[34] R. K. Watt, P. W. Ludden, J. Biol. Chem. 273 (1998) 10019-10025.

[35] J. Xia, J. F. Sinclair, T. O. Baldwin, P. A. Lindahl, Biochemistry 35 (1996) 1965-1971.

[36] W. Shin, P. A. Lindahl, Biochemistry 31 (1992) 12870-12875.

[37] W. Shin, P. A. Lindahl, J. Am. Chem. Soc. 114 (1992) 9718-9719.

[38] W. Shin, P. R. Stafford, P. A. Lindahl, Biochemistry 31 (1992) 6003-6011.

[39] W. Shin, M. E. Anderson, P. A. Lindahl, J. Am. Chem. Soc. 115 (1993) 5522-5526.

[40] P. A. Lindahl, Biochemistry 41 (2002) in press.

[41] D. L. Roberts, J. E. James-Hagstrom, D. K. Garvin, C. M. Gorst, J. A. Runquist, J. R. Baur, F. C. Haase, S. W. Ragsdale, Proc. Natl. Acad. Sci. USA 86 (1989) 32-36.

[42] S. W. Ragsdale, J. R. Baur, C. M. Gorst, S. R. Harder, W. P. Lu, D. L. Roberts, J. A. Runquist, I. Schiau, FEMS Microbiol. Rev. 87 (1990) 397-402.

[43] Y. A. Begg, J. N. Whyte, B. A. Haddock, FEMS Microbiol. Lett. 2 (1977) 47-50.

[44] J. Sambrook, E. F. Fritsch, T. Maniatis, Molecular Cloning - A Laboratory Manual (Second Edition) (Irwin, N., Ed.) Cold Spring Harbor Laboratory Press, New York (1989) Chapter 18.

[45] W. Shin, P. A. Lindahl, Biochim. Biophys. Acta 1161 (1993) 317-322.

[46] H. -K. Loke, G. N. Bennett, P. A. Lindahl, Proc. Natl. Acad. Sci. USA 97, 12530-12535.

[47] M. L. Mole, D. L. Hunter, P. Gao, C. Lau, Analytical Biochem. 259 (1998) 245-252.

[48] K. Fukuyama, Y. Nagahara, T. Tsuikihara, Y, Katzube, T. Hase, H. Matsubara, J. Mol. Biol. 199 (1988) 183-193. 
[49] J. A. Maupin-Furlow, J. G. Ferry, J. Bacteriol. 178 (1996) 6849-6856. 


\section{Figure Legends.}

Fig. 1. a) Arrangement of acs genes in C. thermoaceticum as was known prior to this study (adapted from [48]) including orf7 and $a c s F$.

Fig. 2. Alignment of Orf7 and its Homologs. Ar.f-1, A. fulgidus (Accession Code NP_069525);

Ar.f-2, A. fulgidus (NP_068851); M.1, M. loti (NP_102877); S.m., S. meliloti (CAC46567).

Selected Conserved Residues have been highlighted.

Fig. 3. Alignment of AcsF and its Homologs. Mt.t-1, M. thermoautotrophicum (Accession Code A69096); Ar.f-1, A. fulgidus (NP_069214); Ms.t-1, M. thermophila (AAG53712); Ms.t-2, $M$. thermophila (AAC44653); M.j-1, M. jannaschii (Q58098); Mt.t-2, M. thermoautotrophicum (B69016); Ar.f-2, A. fulgidus (NP_070513); R.r, R. rubrum (P31897); M.j-2, M. jannaschii (Q58233); M.j-3, M. jannaschii (Q60392); Mt.t-3, M. thermoautotrophicum (F69175).

Selected Conserved Residues have been highlighted and the P-loop region has been underlined.

Fig. 4. SDS-PAGE Gel (12\%) of A) Standard Marker, B) AcsF-GST, C) GST.

Fig. 5. a) AcsF-catalyzed hydrolysis of ATP; ATP assay mixtures containing i) AcsF-GST, ii) GST, and iii) no protein; b) AcsF-catalyzed hydrolysis of GTP; GTP assay mixtures containing i) AcsF-GST, ii) GST, and iii) no protein (refer to Experimental Section for details). Residual levels of ADP, due to traces found in the stock ATP solution, have been removed. 
Table 1.Activity of purified recombinant AcsAB obtained for different supplementation levels of $\mathrm{NiCl}_{2}$ in E. coli growth medium.

\begin{tabular}{lcc}
\hline Gene & $\mathrm{Ni}(\mu \mathrm{M})$ & $\mathrm{CO}$ oxidation activity $\left(\mathrm{Umg}^{-1}\right)$ \\
\hline$a c s A B$ & 500 & $>200$ \\
$\operatorname{acs} A B-h y p B$ & 500 & $>200$ \\
$\operatorname{acs} A B$ & 5 & $<10$ \\
$\operatorname{acs} A B F$ & 5 & $<10$ \\
$\operatorname{acs} A B F$ & 500 & $>200$ \\
\hline
\end{tabular}


Figure 1.

acs operon

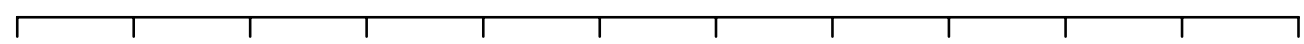

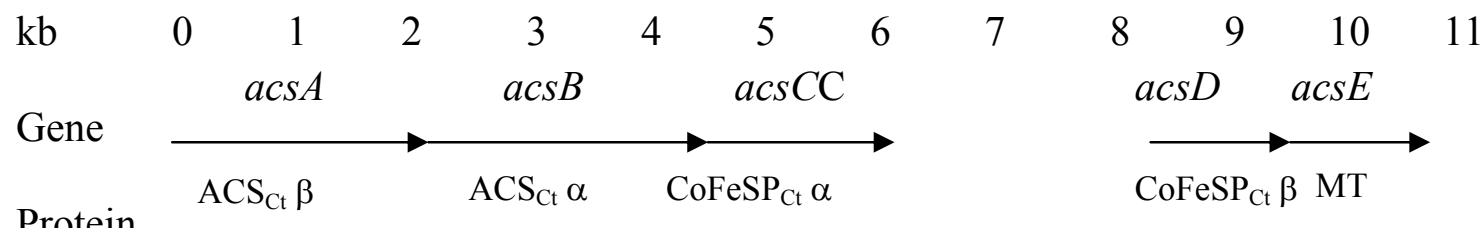

Protein

$\underset{\text { Orf7 }}{\stackrel{\operatorname{orf7C}}{\operatorname{AcsF}}} \underset{\text { acsFC }}{\longrightarrow}$


Figure 2.

Orf 7

Ar.f-1 Ar.f-2 M. 1

S.m

Orf7

Ar.f-1

Ar.f-2

M. 1

S. m

Orf 7

Ar.f-1

Ar.f-2

M. I

S.m

Orf 7

Ar.f-1

Ar.f-2

M. I

S.m

Orf7

Ar.f-1

Ar.f-2

M. 1

S.m

Orf7

Ar.f-1

Ar.f-2

Ar. $\mathrm{f}$

S.m

Orf 7

Ar.f-1

Ar.f-2

M. I

S.m
10

40

60

80

90

100

--MPV DQFAVTFLPD NITVRVAAGT SIMEAANQAG LPLKSTCGGA GTCGRCAIKV QEG---KVE- V-RGGHL-PA RLREE----- -----GYSLA -MPIITELPS GKRAEVDEGK TILSAAQEIG EGIRSLCGGK GSCGKCLVVV RKG---DVEI LSEEAHE--K FVREK----- -----GYYLA --MNSPANI IDPLVLEPS GKRGREPG 作

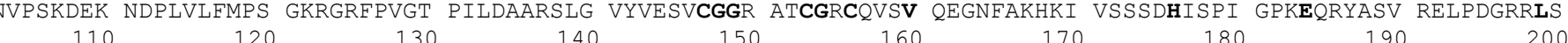

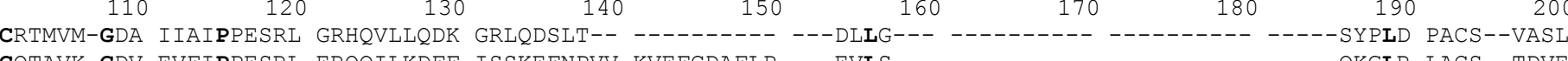

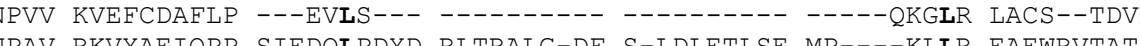
KLLR EAEWRVTAT CSAQIL-GDL VIDVPQDTVI NAQTIRKDAD TRVIARDTAI RMCYVEIEEP DMHKPLGDLD RLKIALMKDW GFKNLEFDFY LLPQVQGILR KGNWTATAAI
CSSQIL-GDL VIDVPQDTVI NAQVVRKAAS DRVIERNAAV QLCYVEIDEP DMHKPLGDLD RMKAVLEKDW GWKDLLIAPH LIPQVQGILR KGNWAVTAAI

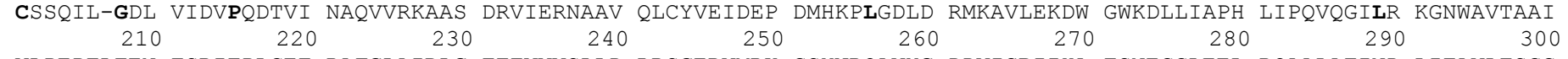
VLPEPTLTEN TSRITPLGET RAFGLAIDLG TTTVVVSLLD LRSGERVMRK GSYNRQAVYG DDVISRIIHA TSNEGGLEEL RQAALATIND LITAVLTSGG EGDFGLVVRG KEVIDVLPDE KAFGLAVDVG TTTIVAALVD LKDGKVVNVA SDYNGQIIYG EEVLSRVEFA RSRKDGVEVL QRAVVESINK LIDKLL-EGY WNGRLIDLE- KG--DVS-D- RCYGVAVDVG SSKIICHLVD LKSGETIATG YSDNPQVAYG EDIVSRITYA SKSAENRKRL QTVVVETVNQ IIAELCNESG HKDADSDIAR VIALWPGLKN EAYGLACDIG STTIAMHLVS LLSGRVAASS GTSNPQIRFG EDLMSRVSYV MMNPDGREGM TVAVREAISS LVDKVCAEGN HRDMDSSRPF IVALWPGLKN EAYGVACDIG STTIAMHLVS LLSGRIVASS GTSNPQIRFG EDLMSRVSYV MMNPDGREAM TKAVREALNG LIGKVCAEGE

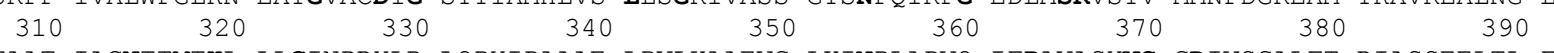

IDPAEVTAAT IAGNTTMTHL LLGINPRYLR LQPYIPAAAE LPVLKAAEVG LKINPLAPVQ IFPAVASYVG GDIVSGALFT RIASSEELTL FIDIGTNGEM ATPDRIYDVV AAGNTIMTHF LVGKDVEYLF SSPDVKVERE GFVVNASEIG LKVNSNAELF CLPPVGRFVG GDIVGDILAS RIVDSATISL MVDLGTNGEI VDLRHVYEVM IVGNSVMHHL FFGIEPRFIG VSPFTPAVRR GVSFPAEDVG LRINRKGYVS SLPLVAGFVG ADAVANIAIT GIHKAEEISM VIDIGTNTEI VQRNDILDSV FVGNPIMHHL FLGIDPTELG GAPFALAVSG AVRIKASDIG LKLNQGARLY MLPCIAGHVG ADAAAVTLSE GPHRQDEMML IVDVGTNAEI

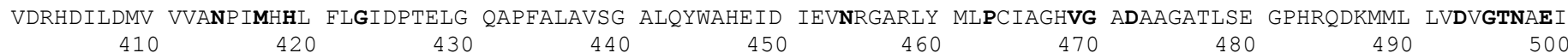

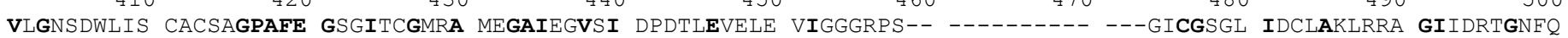

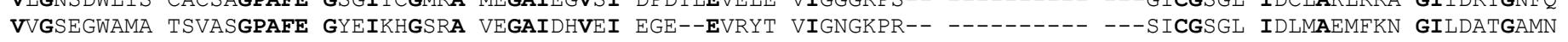
VIGNREKLGV CSAPSGPAFE GAHITFGMKA ISGAIDSVRI ERD--EVIYT TIDNAKAK-- ---.----- ---GLCGTGL IDLIAELYRN GIINRNGKFV VLGNRARVVA ASSPTGPAFE GAEISGGQRA APGAIERVRI DPDTLEPKYR VIGSELWSDE PGFLDSVQAT GVTGICGSGI IEIVAEMYLA GIISEDGVVD VLGNRERVVA ASSPTGPAFE GAEISSGQRA APGAIERVRI DPETLEPRFR VIGVDKWSNE EGFAEAAAAV GVTGICGSAI IEVVAEMYLT GIISQDGVVD 510 520 530 540 560 570 580 590 600
$-K Y I$ EVATPRLRTT DEG-PEFVLA WATQSSTQRD IVLTAADIKN LIRSKGAVFA GIQSLLKTVS LEIDAIERII IAGGFGNYLH IPNAVEIGLL PDLPPE-KYI KDH---SRI I VDGVPKFVVA KAEETEFGKP ITVSEKDINE IMAKGAIKS GWMTLSERLG IFPDKTERTY IAGSEGRHN VENAKVIGLI PDIPSE-KIT GSLAARSPRV TANGRTFSYV LKEGEP--K- ITITQTDVRA IQLAKAALYA GTKLLMEKQN TE--HVDRIH FAGAFGSFID PKYAMVLGLI PDCDLD-KVS GAMVAKSPRI IPNGRTFSYL LHEGEQ--R- ITVTQNDIRA IQLAKSALYA GIKLLMEKQG --VDHVDTIR FAGAFGSFID PKYAMVLGLI PDCDLT-EVK 620 630 640 650 660 670 680 690 700

FAGNTSLKGA ELALLSQPAW QETLELARRM TYLELSAGNL FMEEFVSALF LPHTRLELFP SVGNGSGDER RSG-c-cFAGDTAVGGA KMALKSVRVR DEMEDVVSRL NYVELSVEKN FYSVFVRAIP I-

AVGNAAGAGA RMALLNRGYR REIEETVSQI EKIETALEPK FQEHFVYAMA LPN-KVDPFP KLSAAVKLPP RKTVSEDGIA GDATPRRRRE GHAARRSREAVGNAAGTGA LMALLNRGHR REIEQTVRKI EKIFTAIFSK FOEHFVNAMA MPN-KVDAFP KLAEVVTLPA RKSLTDDGGE GSGRRRRRSR E------- 
Figure 3.

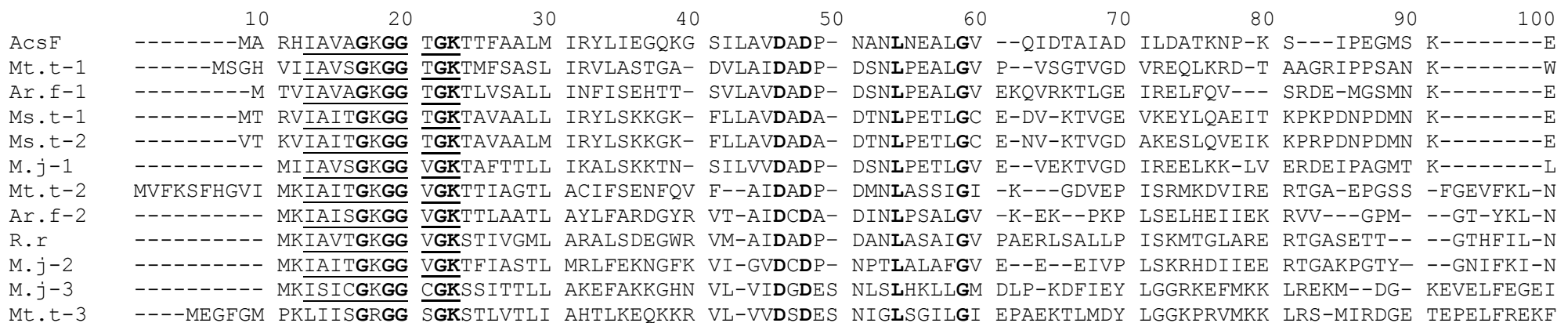

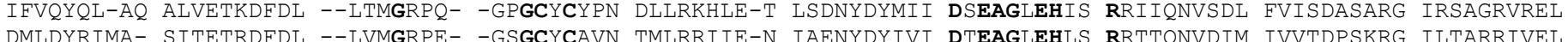
DWLARIMA- SIIETRDFDL --LVMGRPE- -GSGCYCAVN TMLRRIIE-N IAENYDYIVI DIEAGLEHLS RRITQNVDIM IVVIDPSKRG ILIARRIVEL QWLEGKIYE AICECPRYDL --LVMGRPE- -GEGCYCFAN SLLRGVLK-R LMRHYEYIII DTEAGLEHFS RKTIDSADYI IIVTDMSRKG LATAKRIKEL $\begin{array}{lllll}\text { SILKSKVY-E } & \text { IIEEMPGYDL --LVMGRPE- -GSGCYCYVN NLLRGIMD-K LITNYDVVII DAEAGLEHFS RKIIRDIDDL IVVTDASRRG FRTAERIREL } \\ \text { SILKSKVY-E } & \text { VIEEMPGYDL --LVMGRPE- -GTGCYCYVN NLLRGIMD-K LIVNYDLVVI DAEAGLEHFS RKILRDIDDL LVVTDASRRG FOTAERIREL }\end{array}$ DYLRSKIF-E ILVETKYYDL --LVMGRPE- -GSGCYCSVN NWLRQIID-N LAKDYEFVVI DTEAGLEHLS RRTTQNVDVM IVITDASKRG LGTAKRIKKL PRIGDLPDSL SIEHPLRPGL RVMVMGTVEH GGEGCVCPAS VLLKALLRHL ILRKDEMVIL DMEAGIEHLG RRTAESVDLM VVVVEPGLKS LETAERIKKL PKVDDVFEEY SVYNED--GV RVLVLGTIEK GGEGCFCPEN AFLRAILRHA IFKREDVLIL DMEAGIEHLG RGTARGVDLL IAVVEPGTRA VETLERIEKL PRVDDIPEQF CVDHAGIK-L --LLMGTVNH AGSGCVCPEH ALVRTLLRHI LTKRKECVLI DMEAGIEHFG RGTIEAVDLL VIVIEPGSRS LQTAAQIEGL PKVDDLIDKV GYKIGNIT-L --LVMGTIEE GGEGCVCPAS VLLRRLLRHL ILKRDEVVIL DMEAGIEHFG RKTIDTVDLM LIVIEPTKKS LITAKRMKKL SIDSLPKEYL VEK-DNIK-L --LAIGKIHD FGEGCACPMG ALLREFLKSL KLKDKEVVIV DTEAGIEHFG RGVEGGCDVI IAIIDPTYES IRLSKKIEEI DLESLSQEFV CWVG-SLG-L --MQIGKIDH AMEGCACPMG AVTRDFLNHV RLEEDQWVLV DTEAGVEHFG RGIVEGADAV VMVVDPSSDA VLLAEKAAKL

$$
210
$$

230

240

250

260

270

280

290

Acs $F$

Mt. $t-1$

Ar.f-

Ms.t-

Ms.t-2

M.j-1

Mt.t-2

Ar.f-2

R.r

M.j-2

M. j-3

VQELLPINN LYLIVTKIT- GDIAPLQ-EE IERTGIPLIG VTPYDEQIVD YDIHSKPLFD LPATSVSVQA VKAILARCQF -------

ASELKLNFKK IFLIANRIAS EDAEKTIREF AKEEGLELLG VLPYDSSVAE IDLRGEPVSK IDKNSEVYRK MKDVANLMLN LSAKAR----

VEELDSNIGR IHVIANKVTD ANREELIKL- AEDLKLNMIG MIPLDPKIEE MDIKGIPLFK IPDDSIAAVE IESIVKKLGF --.-----

VNEIDSNVGR IVVIANKVDD ANREELIKL- AEDLKLNMIG MIPLDPKIEE MDIKGIPLIK IPDDSIAAVE IESIVKKLGE

VNELDNVGR IHVIANKVTD ANRQEIVKL- AGELKLNLIG VIPLDPKIEE MDIKGIPLFE IPDDSVAAVE IEKIVQKLGI

NELEVKFKD IYVVANKVKP EYEELI-DNY AKELGLNLIG KLPYNKEIAE YDLKGIPLWN LPENNEVYKK VEEIAEKIIN KKF------

AGDIG--VKR IMAVINKVSD IHEEEFMRER LASLNLEVLG SVPRDEKVIA ADMRGEPLMM YPD-SEALRS IRDISERIIS LQEEVG----

ARDLG--IKT ICHIANKLAS PVDVGFILDR A-DQ-FDLLG SIPFDSAIOA ADQAGLSCYD LSPACRDKAH ALMAALIFRV GPTOGVS---

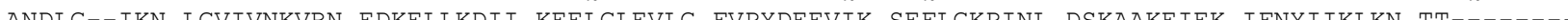

ANDLG-IKN LGVIVNKRN EDKELLKDII KEELGLEVLG TVPDEEVIK SEFLGKPINL DSKAKEIEK IFNYIIKLKN TT--------

THEAD---KR FGVILNKIDE ETEPILTELL TSE-GNEIKG VLPYSPAITK MNLKGESLGA YAVKNEVDEI IRELMKC-.- 
Figure 4.

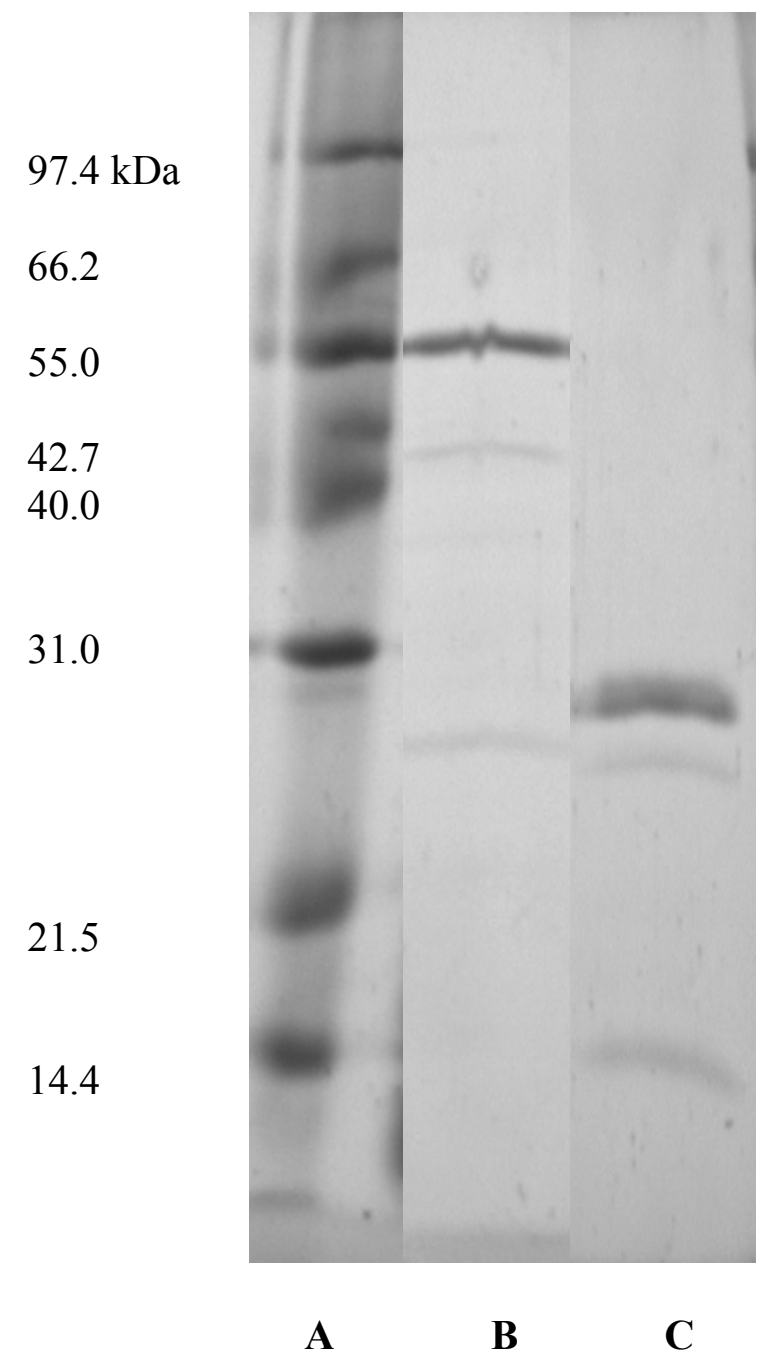



Figure 5.
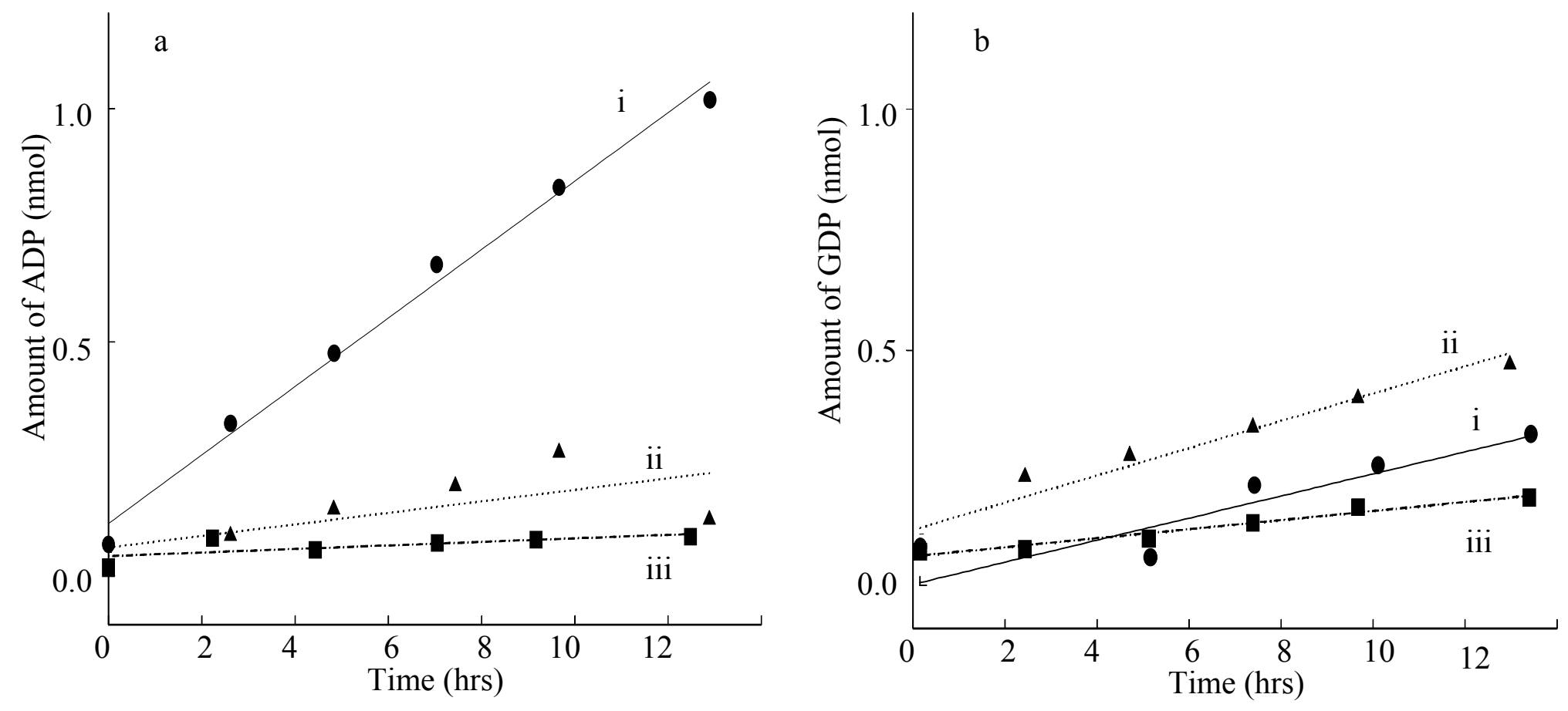